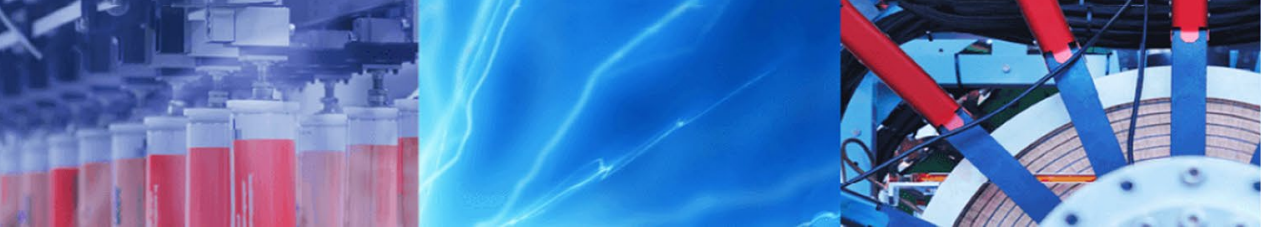

Research Article

\title{
Investigation of bismuth silicate glass system modified by vanadium and copper cations for structural and gamma-ray shielding properties
}

\author{
H. A. Saudi ${ }^{1} \cdot$ Hossam Mohamed Gomaa $^{2}$ M. I. Sayyed ${ }^{3} \cdot$ I. V. Kityk ${ }^{4}$
}

(c) Springer Nature Switzerland AG 2019

\begin{abstract}
A new type of modified bismuth silicate glass has been manufactured with vanadium and copper cations in a traditional rapid cooling method. FTIR spectra have been used to identify the different structural units of this glass. The spectral analysis showed the presence of $\mathrm{BiO}_{3}$ and $\mathrm{BiO}_{6}$ as basic structural units in all studied samples and the presence of bismuth as a former the glass network with silica. The radiation shielding properties were explored using a narrow beam transmission method in $0.662,1.173$ and $1.33 \mathrm{MeV}$. The effective atomic numbers for the sample containing the highest $\mathrm{CuO}$ ratio showed higher energy values than the other studied samples studied. The mean free path of the prepared glasses has been compared to other commercial radiation shielding. The comparison indicates that the glasses produced are more efficient in relation to radiotherapy compared to conventional commercial radiation protection glass. Microhardness measurements were made of the glass recorded at load at $300 \mathrm{~g}$. The replacement of $\mathrm{CuO}$ by $\mathrm{V}_{2} \mathrm{O}_{5}$ has been found to increase the cross-link density in addition to the observed difference in the atomic mass of $\mathrm{Cu}$ and $\mathrm{V}$, thus increasing the hardness.
\end{abstract}

Keywords FTIR · Silicate glasses $\cdot$ Refractive index $\cdot$ Gamma radiation

\section{Introduction}

Recently, radiation shielding has become a subject of interest among many applications in which radiation is being used, for instance, nuclear power plants, industry, academic and scientific applications, and radiotherapy. Since glass is a solid and transparent material, researchers try to develop a new type of glass system that can protect users against certain amounts of radiation without loss of transparency. This type of glass has been developed to accomplish double tasks possessing high transparency. The knowledge of gamma-ray interaction parameters like the mass attenuation coefficient and half value layer is extremely important in the field of radiation shielding materials [1-5]. Good thermal stability and high density of the bismuth-based silicate glass encourage many studies to be undertaken to understand their radiation shielding efficiencies. Interest in bismuth-silicate glasses has increased due to their unique optical features $[6,7]$.

Glasses containing transitional metal (TM) ions are interesting properties because of the many oxidation states of these ions in the glass matrix $[8,9]$. Among TM the vanadium pentoxide is one of the most studied material since it is a former network glass [9] their presence in another glass matrix determines the modified network due to $\mathrm{V}^{4+}$ lons.

Glasses containing copper oxide received a lot of attention because of the presence of copper ions in both $\mathrm{Cu}^{+}$ and $\mathrm{CuO}^{2+}$ valence states [10]. The glasses that contain the TM ions were mainly studied because of their interest in

$\triangle$ H. A. Saudi, heba_saudi@hotmail.com; heba_saudi@azhar.edu.eg| ${ }^{1}$ Physics Department, Faculty of Science, Al-Azhar University (Girls Branch), Nasr City, Cairo, Egypt. ${ }^{2}$ Optical Branch, High Institute of Optics Technology, Cairo, Egypt. ${ }^{3}$ Physics Department, University of Tabuk, Tabuk, Saudi Arabia. ${ }^{4}$ Institue of Optoelectronic and Measuring Systems, Faculty of Electrical Engineering, Czestochowa University of Technology, Armii Krajowej 17, 42-217 Czestochowa, Poland.

SN Applied Sciences (2019) 1:218| https://doi.org/10.1007/s42452-019-0197-x 
optical applications, thermal and magnetic applications [8, 11]. Bismuth silicate glass contains mixed TM ions are Interesting since in these glasses there are mixed exchange pairs of $\mathrm{Cu}^{2+}$ and $\mathrm{V}^{4+}$ Pairs on different properties of that glass. Vanadium penta-oxide has attracted attention in recent years because of its potential use as cathode material in solid devices. Direct current (DC) conductivity of vanadium oxide glasses [10].

In recent works, the structure of the bismuth-silicate glasses has been studied by using IR spectroscopic methods. Since all the bismuth-silicate glasses we have identified, two structural units: pyramidal $\mathrm{BiO}_{3}$ and octahedral $\mathrm{BiO}_{6}$ units in different proportion $[12,13]$. On the other hand, it is well known that $\mathrm{SiO}_{2}$ is one of the most common glasses former and is present in almost all important commercially glasses. The introduction of transitionmetal oxide $\left(\mathrm{V}_{2} \mathrm{O}_{5}\right.$ or $\left.\mathrm{CuO}\right)$ in the glass matrix changes the structure of glasses, where the metal oxide is acting as a modifier and can define semi-conducting properties of the glasses [14]. In the literature, different investigators have studied $\mathrm{SiO}_{2}$ based glasses as a promising novel radiation shielding materials. For example, Rahimi et al. [15] reported the radiation attenuation properties for $\mathrm{Ti}$ and $\mathrm{Zr}$ containing lead silicate glasses. The authors have been reporting that the glass sample with $\mathrm{SiO}_{2}$ contents of $26.9 \mathrm{wt} \%$ has good radiation shielding properties. Singh et al. [16] used a narrow beam transmission method to measure the mass attenuation coefficients for $\mathrm{PbO}-\mathrm{SiO}_{2}$ glass system at $0.662,1.173$ and $1.332 \mathrm{MeV}$. They compared the radiation shielding properties $\mathrm{PbO}-\mathrm{SiO}_{2}$ glasses with some types of other concretes. Recently, Bagheria et al. [17] used the MCNP-4C code, XMuDat programs, and XCOM to study the radiation shielding performance of silicate glasses containing $\mathrm{BaO}, \mathrm{PbO}$ and $\mathrm{Bi}_{2} \mathrm{O}_{3}$ within the photon energy range $10 \mathrm{keV}$ to $10 \mathrm{MeV}$. The authors compared their theoretical results with the experimental data reported by other research groups. Besides, Kaur et al. [18] fabricated $\mathrm{Bi}_{2} \mathrm{O}_{3}-\mathrm{B}_{2} \mathrm{O}_{3}-\mathrm{SiO}_{2}-\mathrm{Na}_{2} \mathrm{O}$ glass system using a melt quenching technique and measured the mass attenuation coefficients for the prepared glasses at $662 \mathrm{keV}$. Also, Singh et al. [19] used the geometrical progression (G-P) fitting method to study the exposure build-up factor for bismuth boro-silicate glasses. The authors found that the values of the exposure buildup factor strongly depend on the bismuth concentration and the energy of the incident photons. Tekin et al. [20] used the Monte Carlo code MCNPX to investigate the photon shielding properties of the $\mathrm{B}_{2} \mathrm{O}_{3}-\mathrm{Bi}_{2} \mathrm{O}_{3}-\mathrm{SiO}_{2}-\mathrm{TeO}_{2}$ glass system. They used the MCNPX code to calculate the mass attenuation coefficient at $356,662,1173$ and $1332 \mathrm{keV}$ photon energies. They compared the obtained results with those calculated by XCOM and good agreement between MCNPX and XCOM results were reported. This work aims to study how both
$\mathrm{Cu}^{2+}$ and $\mathrm{V}^{5+}$ cations affect the structural and the radiation shielding properties of some bismuth silicate glasses. The following chemical formula was chosen to achieve the purpose of this study; $x$ wt $\%$ CuO-(30-x) wt $\% \mathrm{~V}_{2} \mathrm{O}_{5}-50$ wt $\%$ $\mathrm{Bi}_{2} \mathrm{O}_{3}-10$ wt $\% \mathrm{Na}_{2} \mathrm{O}-10 \mathrm{wt} \% \mathrm{SiO}_{2}$, where $(0 \leq \mathrm{x} \leq 30)$.

\section{Materials and methods}

\subsection{Preparation of glass}

The chemical formula, $x$ wt $\%$ CuO-(30-x) wt $\%$ $\mathrm{V}_{2} \mathrm{O}_{5}-50$ wt $\% \mathrm{Bi}_{2} \mathrm{O}_{3}-10$ wt $\% \mathrm{Na}_{2} \mathrm{O}-10$ wt $\% \mathrm{SiO}_{2}$, where $(0 \leq x \leq 30)$ was considered to prepare some oxide glasses. For each sample, all components were mixed together and then introduced directly into an electric furnace at $1100^{\circ} \mathrm{C}$ for $2 \mathrm{~h}$.

\subsection{Density and molar volume}

The density of these glasses was measure at room temperature using Archimedes principle. The density of glass samples $(\rho)$ was calculated using the formula

$\rho=\left(W_{2}-W_{1}\right) /\left(W_{4}-W_{1}\right)-\left(W_{3}-W_{2}\right)$

where $W_{1}$ is the weight of empty specific gravity bottle, $W_{2}$ is the weight of specific gravity bottle with saWmple, $W_{3}$ is the weight of specific gravity bottle with sample and distill water, and $W_{4}$ is the weight of specific gravity bottle with distill water.

Molar volume was calculated using the following relation:

$V_{m}=X_{i} M_{i} / \rho$

where $M_{i}$ is the molecular weight of the ith component and $X_{i}$ is the molar fraction of the $i$ th component [21].

\subsection{FTIR measurements}

The FTIR spectra were measured, for all samples, at ambient temperature in the spectral range $4000-400 \mathrm{~cm}^{-1}$ by a Fourier Transform infrared spectrometer with $1 \mathrm{~cm}^{-1}$ spectral resolution.

\subsection{Attenuation measurements}

The mass attenuation coefficients have been measured using the $\gamma$-ray spectrometer (NUCLEONIX, GR611 M) which includes a detector and multichannel analyzer (NUCLEONIX, MC 1000U). The scintillation detector was a good type $(2 \times 2$ in.) Nal ( $\mathrm{TI})$ crystal with 0.656 " diameter and 1.546" depth. The Nal (TI) detector has an energy resolution equal to about $12 \%$ at $662 \mathrm{keV}$. Radioactive point 
sources ${ }^{60} \mathrm{Co}$ and ${ }^{137} \mathrm{Cs}$ each $5 \mathrm{mCi}$ strength. The online analysis of $\mathrm{Y}$-ray spectrum was performed using Aspect computer software. The source was confined in lead cylinder collimator having $0.52 \mathrm{~cm}$ aperture. Collimator was placed in front of source collimator to produce $0.42 \mathrm{~cm}$ beam. The distance between source and detector was kept fixed at $40 \mathrm{~cm}$. The glasses of thickness $0.5-1.5 \mathrm{~mm}$ were selected and irradiated by $0.662 \mathrm{MeV}$ photons emitted from ${ }^{137} \mathrm{Cs}$ and 1.173 and $1.33 \mathrm{MeV}$ photons emitted from ${ }^{60} \mathrm{Co}$. The incident and attenuated intensities of $\gamma$-rays were measured by recording optimum count $\left(10^{4}\right)$ for fix preset of time. The linear attenuation coefficient $(\mu)$ values for the prepared glasses $\left(\mathrm{CuV}_{1}-\mathrm{CuV}_{7}\right)$ were determined using the next relation [22]:

$\mu_{m}=\frac{\mu}{\rho}=\ln \left(\frac{I_{0}}{l}\right) \frac{1}{\rho t}$

where $I_{0}$ and $I$ are the intensities of the initial and attenuated gamma radiation energies respectively, $\rho$ is the density, and $t$ is the glass sample thickness. The mass attenuation coefficient values were then obtained by dividing the $\mu$ values by the density of the glass samples. From the mass attenuation coefficients $(\mu / \rho)$ we have calculated other shielding parameters such as effective atomic number, half value layers etc. [23]. Additionally, the theoretical values of $\mu / \rho$ were calculated using XCOM software for possible comparison with the experimental obtained values [25]. The effective atomic number is another important parameter that characterize the radiation shielding properties of the certain material. In his work, Hine [26] reported that a single number cannot uniquely describe the atomic number in the several energy regions for any composite materials. This number is known as effective atomic number $\left(Z_{\text {eff }}\right)$ and it is varied with the photon energy. The next relation was used to evaluate the $Z_{\text {eff }}$ for the glass samples under study [27]:

$Z_{\text {eff }}=\frac{\sum_{i} f_{i} A_{i}\left(\frac{\mu}{\rho}\right)_{i}}{\sum_{j} f_{j} A_{j}\left(\frac{\mu}{\rho}\right)_{j}}$

where $f_{i}$ represents the fraction by the mole of each constituent element, $A_{i}$ is the atomic weight and $Z_{j}$ is the atomic number. Besides, the electron density represents the number of electrons per unit mass of the interacting materials. From the calculated $Z_{\text {eff }}$ values, we can calculate this quantity using the following relation:

$N_{e}=N_{A} \frac{n Z_{\text {eff }}}{\sum_{i} n_{i} A_{i}}=N_{A} \frac{Z_{\text {eff }}}{A}$

where $\mathrm{N}_{\mathrm{A}}$ is Avogadro constant and $A$ is the mean atomic mass.
Half-value layer (HVL) and mean free path (MFP) are other two important quantities that describe the effectiveness of radiation shielding. HVL represents the thickness of a glass sample that reduces the initial intensity of the gamma photon to half. Furthermore, MFP is the average distance between two successive gamma photon interactions [27]. The lower is the value of HVL or MFP, more is the interactions of gamma photon with the glass sample, thus the better is the shielding performance of the sample. The next two equations were used to evaluate the HVL and MFP for the prepared glass samples [28]:

$H V L=\frac{0.693}{\mu}$

$M F P=\frac{1}{\mu}$

where $\mu$ is the linear attenuation coefficient.

\subsection{Microhardness measurements}

For all the samples, Vickers hardness $H_{v}=1.8 p / d^{2}$ was measured using a micro hardness tester (Leco AMH 100, USA), where $p$ is the indentation load and $d$ is the diagonal length impression.

\section{Results and discussion}

\subsection{FTIR spectra}

To understand the effect of addition of $\mathrm{CuO}$ in the bismuth silicate glass matrix, by analyzing the infrared. Fourier transform infrared FTIR is one of the most popular tools that is used in the characterization processes for such kind of glasses. FTIR spectroscopic analysis of a certain material gives useful information about the building blocks, the chemical bonds in addition to the nature of the internal structure. Figures 1 and 2 show the FTIR spectra of the all prepared samples. Each spectrum consists of more than one broadband the thing which characterizes amorphous structures. So, it can state that the prepared glasses have short range ordered structures. As it is seen, the FTIR charts show the absorbance as a function of the wave number, where each absorption process has a peak due to the vibration of certain molecular group or chemical bond. Therefore, for all the samples, the multi absorption peaks refer to variables of the structural groups and chemical bonds. Each spectrum was de-convoluted to some of the individual peaks Provided that the sum of areas under these peaks is equal to the total area under the original spectrum, as in Fig. 2 for $\mathrm{x}=0 \mathrm{~mol} \%$. The spectra for all 

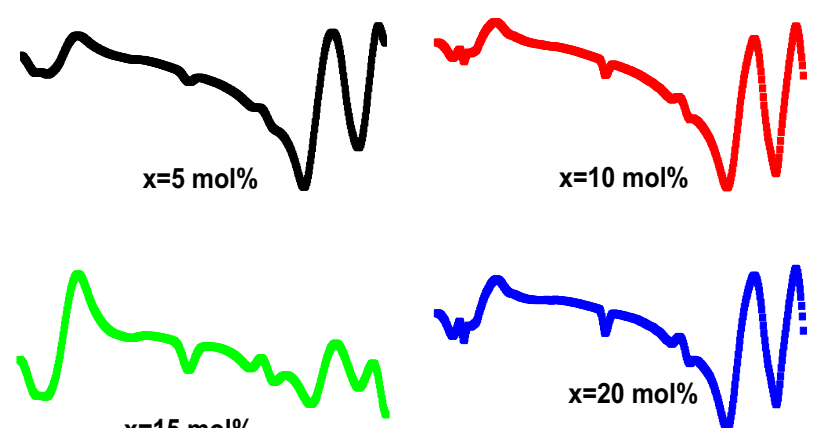

$\mathrm{x}=15 \mathrm{~mol} \%$
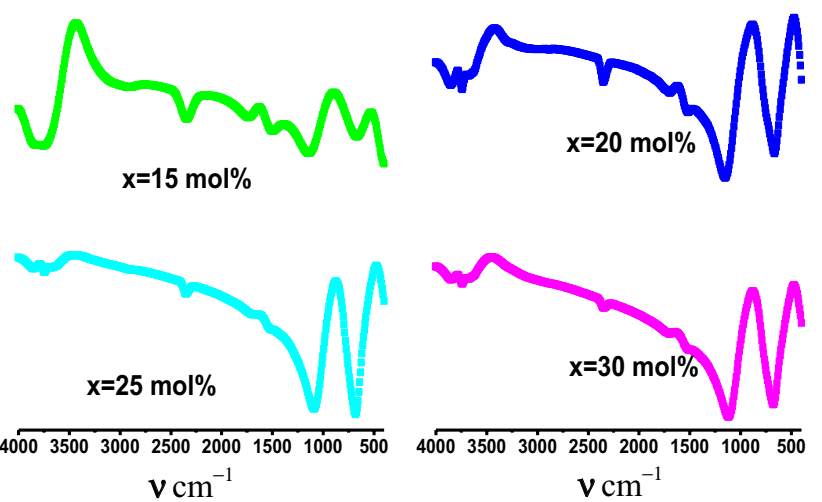

Fig. 1 FTIR spectra for $\left[x C u O-(30-x) \mathrm{V}_{2} \mathrm{O}_{5}-50 \mathrm{Bi}_{2} \mathrm{O}_{3}-10 \mathrm{Na}_{2} \mathrm{O}-10 \mathrm{SiO}_{2}\right]$ glass samples

the samples were de-convoluted by the same way, such that the deconvolution results were recorded in Table 1.

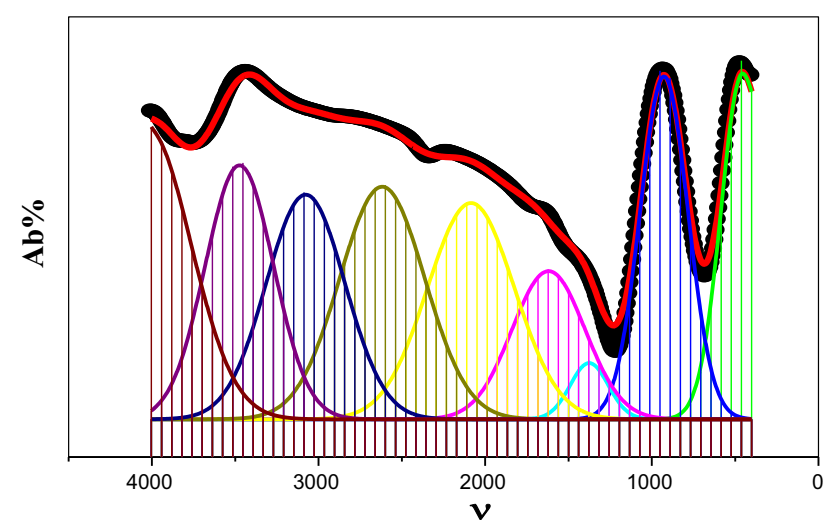

Fig. 2 De-convoluted FTIR spectra for $x=0$ wt $\%$
Looking carefully at the data in this table one can conclude that $\mathrm{Bi}$ cations have two different coordination states $\mathrm{BiO}_{3}$ and $\mathrm{BiO}_{6}$, it means that some of $\mathrm{Bi}^{3+}$ occupied the interstitial vacancies in the glass network as a glass modifier, while some other share in the glass network as a glass former with $\mathrm{Si}^{4+}$ cations. A sub band at around $1000-1050 \mathrm{~cm}^{-1}$ (clearly shown in Fig. 1 was observed in 1st four samples, this is assigned to $V=O$ stretching mode. The position of sub-band remained unchanged by changing the composition of $\mathrm{CuO}$. Another sub-band appears at around $900-950 \mathrm{~cm}^{-1}$, which becomes less broad with increase in $\mathrm{CuO}$ content and is attributed to the vibrations of $\mathrm{VO}_{2-}$ groups of the $\mathrm{VO}_{4}$ polyhedra, while the intense band at $1020 \mathrm{~cm}^{-1}$ is related to the vibrations of the $\mathrm{VO}_{2-}$ groups of the $\mathrm{VO} 5$ group [3]. The absorption band at $600-620 \mathrm{~cm}^{-1}$ (Fig. 1) starting from $15 \% \mathrm{CuO}$ content that can be due to the $\mathrm{Cu}-\mathrm{O}$ bonds $[8,9]$. However, the relative area of this band decreases with increasing of $\mathrm{CuO}$ content. The increasing of $\mathrm{CuO}$ content on expense of $\mathrm{V}_{2} \mathrm{O}_{5}$ results in an increase of the electron cloud density around the oxygen in the $\mathrm{BiO}_{3}$ and $\mathrm{SiO}_{2}$ unit, leading to an increase in the $\mathrm{Bi}-\mathrm{O}-\mathrm{Si}$ band and consequently contributing to the shift towards higher wavenumbers. This process forms new $\mathrm{Si}-\mathrm{O}-\mathrm{Cu}$ bridging bonds due to the induced electrostatic field causing a weakening of the silicate network [29]. The absence of $\mathrm{V}^{5+}$ groups and bonds may be due to two factors: the first is its low relative concentration and the second is it sharing to $\mathrm{BiO}_{6}$ and $\mathrm{Si}-\mathrm{O}-\mathrm{Si}$ in the vibration are equal to about $480 \mathrm{~cm}^{-1}[29,30]$.

\subsection{Density and molar volume}

Any change in the internal structure of the solid material causes a significant change in the value of its density. Therefore, density measurement is one of the crucial tools used to indicate the occurrence of any change in the internal structure of the material. The density values of all prepared glasses were measured and recorded in Table 2 . The density increases gradually with increasing of copper oxide content in the glass compositions. This one confirms that the glass structure becomes more

Table 1 Assignments of principal absorption bands in the infrared spectra of all glass samples

\begin{tabular}{|c|c|c|}
\hline Average band positions & Assignments & References \\
\hline $484 \mathrm{~cm}^{-1}$ & $\begin{array}{l}\text { Stretching vibrations of } \mathrm{Bi}-\mathrm{O} \text { and/or } \mathrm{Bi}-\mathrm{O}-\mathrm{Bi} \text { in }\left[\mathrm{BiO}_{6}\right] \text { octahedral and/or The band } \\
\text { appeared around } 460 \mathrm{~cm}^{-1} \text { can be attributed to the bending vibrations of } \mathrm{V}-\mathrm{O}-\mathrm{V} \\
\text { bridging oxygen bonds. Bending vibrations of } \mathrm{Si}-\mathrm{O}-\mathrm{Si} \text { linkages }\end{array}$ & {$[24,25]$} \\
\hline $895 \mathrm{~cm}^{-1}$ & Symmetrical stretching vibrations of $\mathrm{Bi}-\mathrm{O}$ bonds of $\left[\mathrm{BiO}_{3}\right]$ units & {$[28,29]$} \\
\hline $1336 \mathrm{~cm}^{-1}$ & Stretch vibration in $\mathrm{Si}-\mathrm{O}-\mathrm{Si}$ & [29] \\
\hline Above $1620 \mathrm{~cm}^{-1}$ & $\begin{array}{l}\text { Molecular water } \\
\text { Stretching vibrations of }[\mathrm{OH}] \text { and molecular water }\end{array}$ & {$[30,31]$} \\
\hline
\end{tabular}


Table 2 Nominal compositions, density values, molar volume $V_{m}$, the refractive index $n$ and molar refractivity $R_{m}$ of the synthesized glasses

\begin{tabular}{lcclllll}
\hline Code & $\mathrm{CuO}$ & $\mathrm{V}_{2} \mathrm{O}_{5}$ & $\mathrm{Bi}_{2} \mathrm{O}_{3}$ & $\mathrm{Na}_{2} \mathrm{O}$ & $\mathrm{SiO}_{2}$ & $\rho\left(\mathrm{g} \mathrm{cm}^{-3}\right)$ & $\mathrm{V}_{\mathrm{m}}\left(\mathrm{cm}^{3}\right)$ \\
\hline CuV1 & 0 & 30 & 50 & 10 & 10 & 5.99 & 20.04 \\
CuV2 & 5 & 25 & 50 & 10 & 10 & 6.13 & 48.06 \\
CuV3 & 10 & 20 & 50 & 10 & 10 & 6.28 & 46.10 \\
CuV4 & 15 & 15 & 50 & 10 & 10 & 6.42 & 44.30 \\
CuV5 & 20 & 10 & 50 & 10 & 10 & 6.57 & 42.51 \\
CuV6 & 25 & 5 & 50 & 10 & 10 & 6.71 & 40.86 \\
CuV7 & 30 & 0 & 50 & 10 & 10 & 6.86 & 39.22 \\
\hline
\end{tabular}

tightly packed with increasing $\mathrm{CuO}$ content. This behavior also may be due to the replacement of $\mathrm{CuO}$ (density is $6.3 \mathrm{~g} / \mathrm{cm}^{3}$ with $\mathrm{V}_{2} \mathrm{O}_{5}$ (density is $3.4 \mathrm{gm} / \mathrm{cm}^{3}$ ) [31]. The density values were used to calculate the molar volumes for the prepared glasses. These volumes may be useful for comparison between the stability of the prepared glasses. As seen in Table 2, the value of the molar volume decreases as $\mathrm{CuO}$ is increased. Such behavior may be attributed to two factors: the first is a decrease of the number of oxygen atoms and the second one is the replacement of high ionic radius cation $\mathrm{V}^{5+}$ by short ionic radius cation $\mathrm{Cu}^{2+}$. The decrease of the molar volume values with $\mathrm{CuO}$ content may be an indication to increase of the thermal stability of study glasses in addition to a decrease of their refractive index magnitudes. The density and molar volume results indicate that $\mathrm{CuO}$ has a strong effect on the glass network construction. Both density and molar volume ware used in the following relations to calculate some principle parameters such as the refractive index $n$ and molar refractivity $R_{m}[32,33]$ :

$\chi_{\text {glass }} \sum_{i=1}^{N} \frac{n_{i} \chi_{i}}{N} r_{j}$

$\mathrm{n}_{\text {gomaa }}=3.44 \frac{\mathrm{A}}{\mathrm{B}}\left(\frac{1}{\mathrm{~V}_{\mathrm{m}}}\right)^{-0.1 \chi_{\text {glass }}}$

where $\chi_{i}$ refers to Pauling electronegativity, $n_{i}$ is the number of atoms of ith elements while $\mathrm{N}$ is the total atoms in the chemical compound, $r j$ is molar fraction of the oxide $j$ th in the glass matrix. In Eq. $7 \mathrm{n}_{\text {gomaaa }}$ represents the glass refractive index, $A$ and $B$ are the numbers of cations and all atoms in the glass chemical formula, respectively. Following the Table 3 it can be observed that each sample has ratio $R_{m} / V_{m}<1$ which means non-metal nature [34] random network structure. The values of the electronegativity were observed to decrease with increasing $x$ values. The important thing which may cause the decrease in the number of the oxygen atoms, may be a result of replacement $\mathrm{V}_{2} \mathrm{O}_{5}$ by $\mathrm{CuO}$. Also, it can be observed that
Table 3 Electronegativity and refractive index

\begin{tabular}{llll}
\hline Code & $\chi$ & $\mathrm{n}$ & $\mathrm{Rm} / \mathrm{Vm}$ \\
\hline CuV1 & 2.79 & 2.60 & 0.658 \\
CuV2 & 2.77 & 2.56 & 0.650 \\
CuV3 & 2.76 & 2.52 & 0.641 \\
CuV4 & 2.75 & 2.48 & 0.632 \\
CuV5 & 2.74 & 2.44 & 0.623 \\
CuV6 & 2.72 & 2.40 & 0.614 \\
CuV7 & 2.71 & 2.37 & 0.605 \\
\hline
\end{tabular}

the calculated refractive index shows slightly decrease with increasing $\mathrm{CuO}$ content This result may mean that the increase of $\mathrm{Cu}^{2+}$ content favor a decrease of the optical band gap for the studied glasses, Since the refractive index depend on the electronegativity value which has direct dependence on the optical band gap according to the following relation 7 [34]. In other word the increase of $\mathrm{Cu}^{2+}$ content is expected to improve the nonlinear optical properties of the studied glasses.

$\chi=0.2688 E_{o p t}$.

\subsection{Photon interaction parameters}

Gamma-ray linear attenuation coefficient $(\mu)$ determines the absorption of gamma-rays in unit length of an absorbent material. $\mu$ strongly depends on the energy of the incident energy gamma-ray and the density of the absorptive material. Photon penetration in matter is governed statistically by the probability per unit distance $\mu$ propagated that a photon interacts by one physical process or another. Gamma-ray attenuation graph for the absorbers of $\mathrm{CuV}_{2}$ glass sample (as an example) from the spectrometer are shown in Fig. 3. The slope of the absorption graph gives the experimental gamma-ray linear attenuation coefficient $\mu$ for $\mathrm{CuV}_{2}$ glass sample. From the measured $\mu$ and the density of the glass samples, we calculate the experimental mass attenuation coefficient values, and we can denote it by $(\mu / \rho)_{\text {Exp. }}$. To test the validity of the experimental results, the values of the $\mu / \rho$ for the prepared glasses were calculated by the XCOM program. The $(\mu / \rho)_{\operatorname{Exp}}$ and 

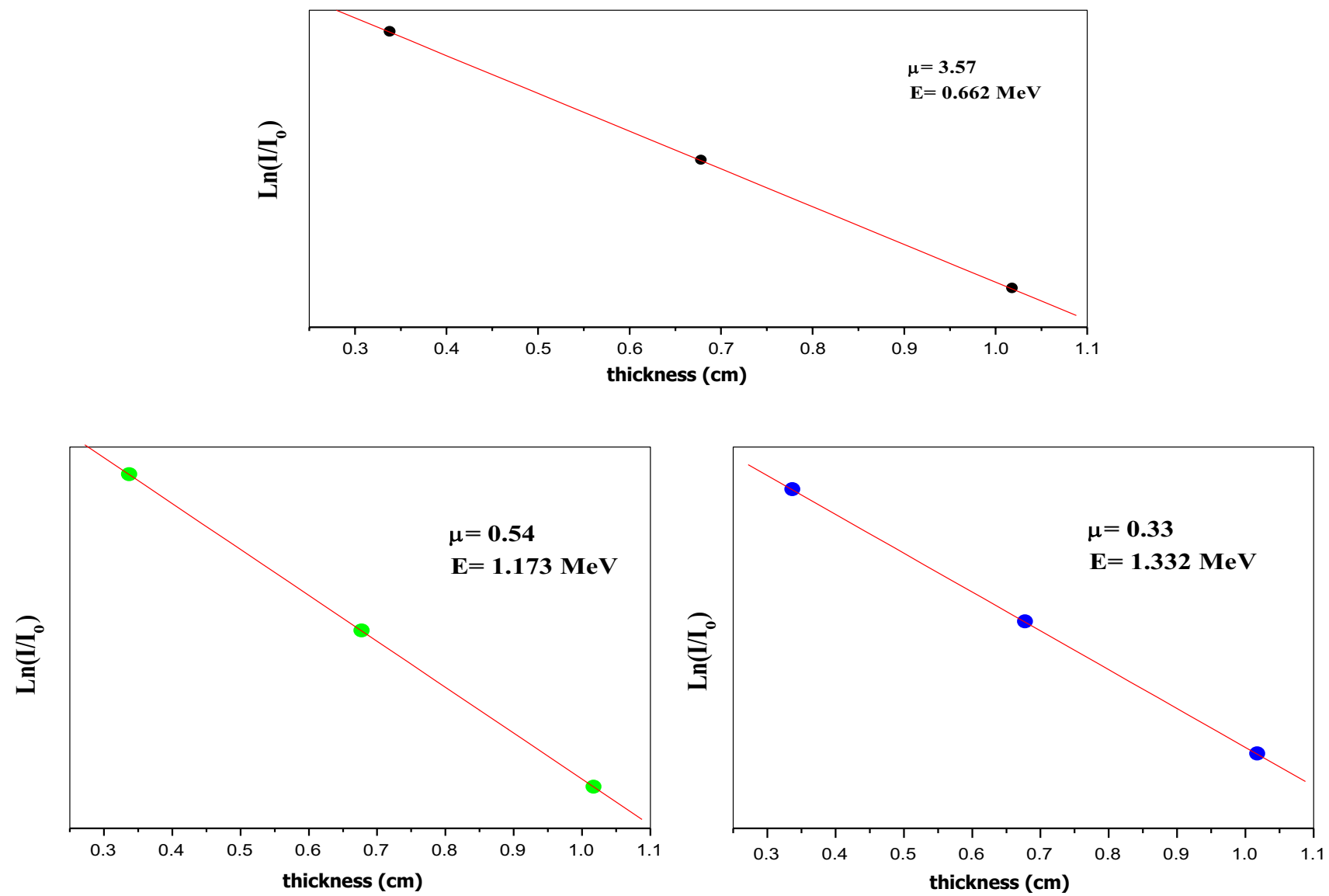

Fig. 3 Gamma-ray attenuation graphs for $\mathrm{CuV}_{2}$ glass sample

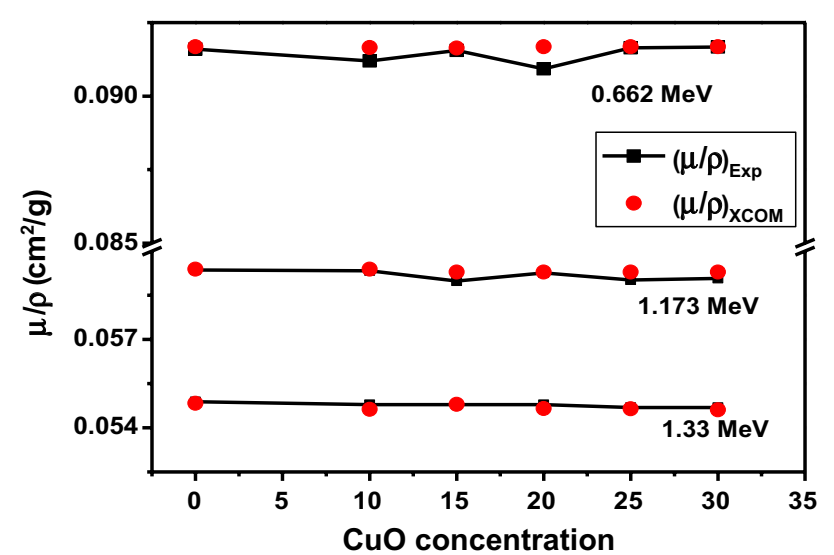

Fig. 4 Comparison of the experimental mass attenuation coefficients $(\mu / \rho)\left(\mathrm{cm}^{2} / \mathrm{g}\right)$ of the prepared glasses and the simulated XCOM results

$(\mu / \rho)_{\text {xсом }}$ at 662,1173 and $1332 \mathrm{keV}$ are plotted and presented in Fig. 4.

It can be seen that the $\mu / \rho)_{\text {Exp. }}$ and $(\mu / \rho)_{\text {Xcom }}$ coincides with each other at the given photon energies. Also, the difference between $(\mu / \rho)_{\text {Exp }}$ and $(\mu / \rho)_{X c O M}$ values were evaluated using the next relation:

Difference $=\left|\left(\frac{(\mu / \rho)_{X C O M}-(\mu / \rho)_{\text {Exp }}}{(\mu / \rho)_{X C O M}}\right) \times 100 \%\right|$

The differences between both the experimentally determined and theoretically calculated $\mu / \rho$ values are found in the content range of $0.87-8.30 \%, 1.58-7.74 \%, 0.76-8.87 \%$, $0.75-8.89 \%, 0.65-8.56 \% 0.54-8.76 \%$ and $0.55-8.80 \%$ for $\mathrm{CuV}_{1}-\mathrm{CuV}_{7}$ glasses, respectively. The differences between the experimental and theoretical (XCOM) results are small and this validates the narrow beam transmission method used in this work. Also, it is evident from Fig. 4, that the $\mu / \rho$ values for the $\mathrm{CuV}_{1}-\mathrm{CuV}_{7}$ glasses decrease with the increase of the energy of the photon. The $Z_{\text {eff }}$ values for the prepared glasses are shown in Fig. 5, where the present $Z_{\text {eff }}$ results have the same trends as Yasaka et al. [35] who measured the $Z_{\text {eff }}$ of zinc bismuth borate glasses within the energy range $0.223-0.662 \mathrm{keV}$. The range of $\mathrm{Z}_{\text {eff }}$ as depicted in Fig. 4 are 18.16-20.77, 18.60-21.25, 19.07-21.77, 19.56-22.30, 20.07-22.86, 20.61-23.46 and 21.18-24.08 for $\mathrm{CuV}_{1}-\mathrm{CuV}_{7}$ glasses, respectively. Besides, 


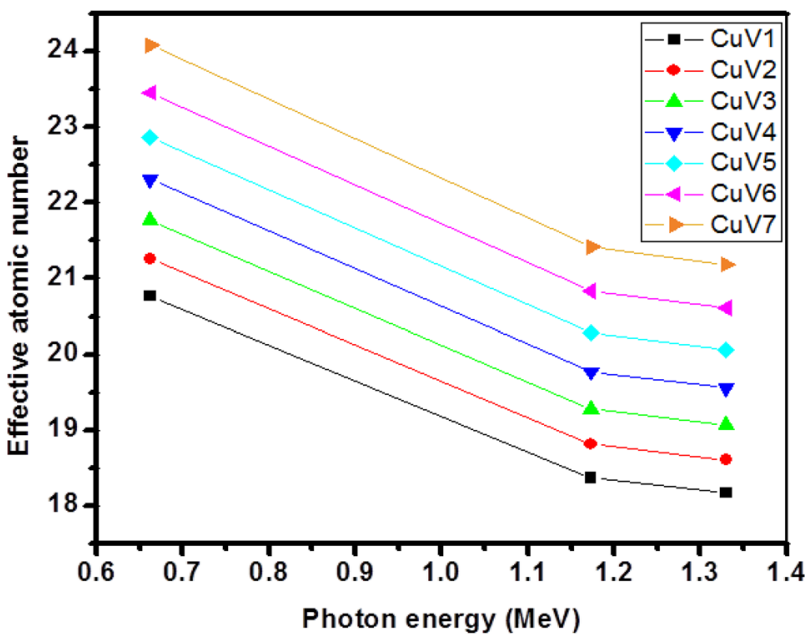

Fig. 5 The effective atomic number for the prepared glasses

the $Z_{\text {eff }}$ values are found to increase with increasing $\mathrm{CuO}$ content.

The increase in $Z_{\text {eff }}$ is referring to the replacement of $\mathrm{V}_{2} \mathrm{O}_{5}$ by $\mathrm{CuO}$ which has a higher effective atomic cross section than $\mathrm{V}_{2} \mathrm{O}_{5}$. Also, it should be noted that the $\mathrm{Z}_{\text {eff }}$ decrease with increasing photon energy for all the prepared glasses $\left(\mathrm{CuV}_{1}-\mathrm{CuV}_{7}\right)$, which means that there are more interactions of the glass sample with low energy photons. Moreover, the $Z_{\text {eff }}$ at $0.662 \mathrm{MeV}$ are higher for all the titled glasses than for other photon energies due to the photoelectric absorption probability, which is very high at $0.662 \mathrm{MeV}$. This is since the increase in the energy of photon makes it be able of deeply penetrating in the glass sample [36]. From Fig. 5, it is obvious that CuV7 (contains a maximum $\mathrm{CuO}$ concentration) glass sample possesses the highest $Z_{\text {eff }}$ values among the prepared glass samples, which means that this sample show superior shielding properties. Thus, the radiation shielding properties of the glass system under study are enhanced with increasing $\mathrm{CuO}$ content.

The variation of HVL for the studied glasses is given in Fig. 6 versus photon energy. This figure shows an increasing trend of HVL for the prepared glass materials with the increasing of photon energies from 0.662 to $1.33 \mathrm{MeV}$. This one indicates that that the photons with higher energies have an ability to penetrate deeper to the glass sample in comparison with the lower photon energies. Also, it is clear from Fig. 6 that the increment of $\mathrm{CuO}$ for the glass samples leads to decrease in the HVL values. Following the Table 2 , the density of the glass samples increases while the $\mathrm{CuO}$ content increases gradually, and it is well known that the $H V L$ value is inversely proportional to the density, implying that the addition of $\mathrm{CuO}$ reduces the HVL hence improves the radiation shielding properties for the prepared glasses,

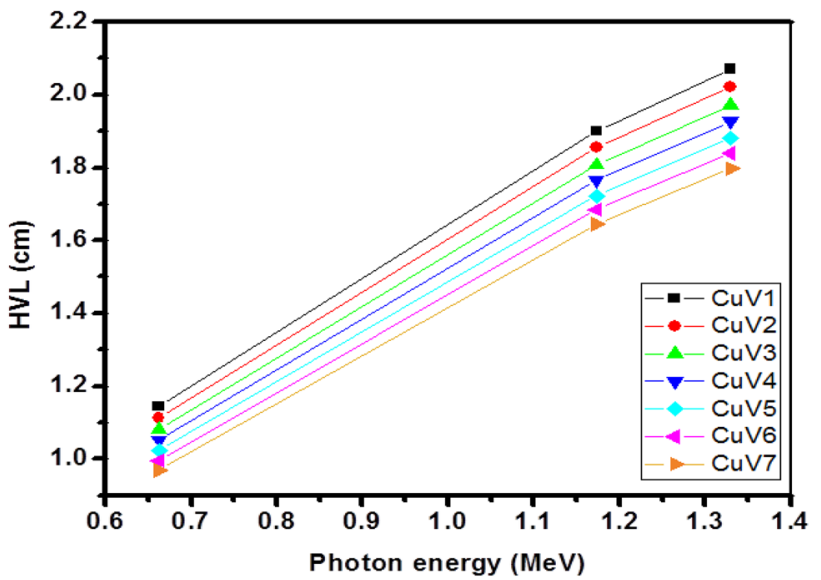

Fig. 6 The half value layer $(\mathrm{cm})$ for the prepared glasses

as previously verified by Kurudirek et al. [1]. Besides, it is revealed that the CuV1 glass sample has the highest values of $\mathrm{HVL}$ (in the range of $1.14-2.07 \mathrm{~cm}$ ), while $\mathrm{CuV}_{7}$ sample (which contains the highest amount of $\mathrm{CuO}$ ) possesses the lowest values of HVL (in the range of $0.97-1.80 \mathrm{~cm}$ ).

Figure 7 introduces the variety of MFP with photon energy for the $\mathrm{CuV}_{1}-\mathrm{CuV}_{7}$ glass samples. In this figure, there is observed decreasing order of MFP from $\mathrm{CuV}_{1}$ to $\mathrm{CuV}_{7}$. This trend of decrease in MFP shows that the increment in the weight percent of $\mathrm{CuO}$ enhances the radiation shielding feature of the prepared glasses. This means that CuV7 has the lowest MFP at all the 0.662, 1.173 and $1.33 \mathrm{MeV}$ photon energies followed by others accordingly. The lower MFP of CuV7 glass sample could be understood from its high percentage fraction of $\mathrm{CuO}$. This result emphasizes that CuV7 sample has superior radiation shielding performance. The MFP of the prepared glasses at $0.662 \mathrm{MeV}$ are $1.65,1.61,1.56,1.52,1.48$,

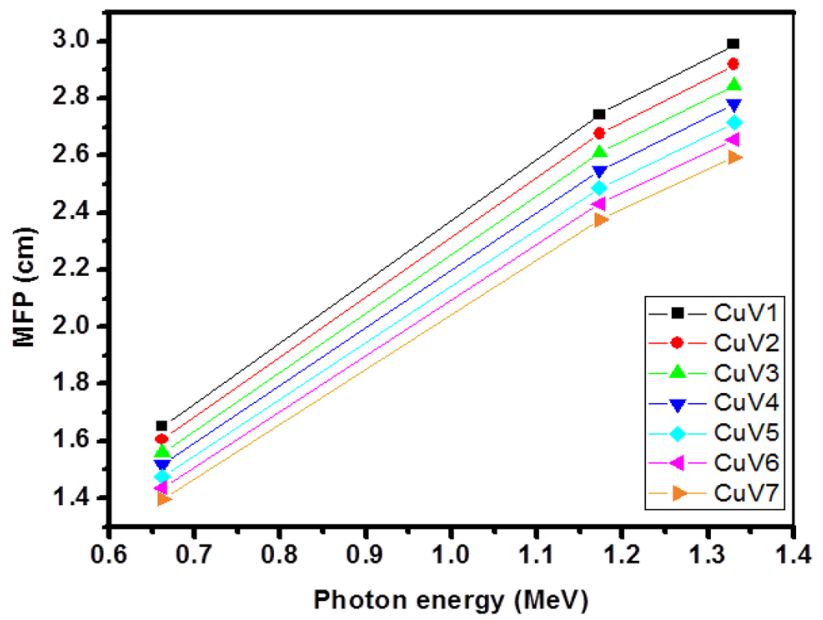

Fig. 7 The mean free path $(\mathrm{cm})$ for the manufactured glasses 


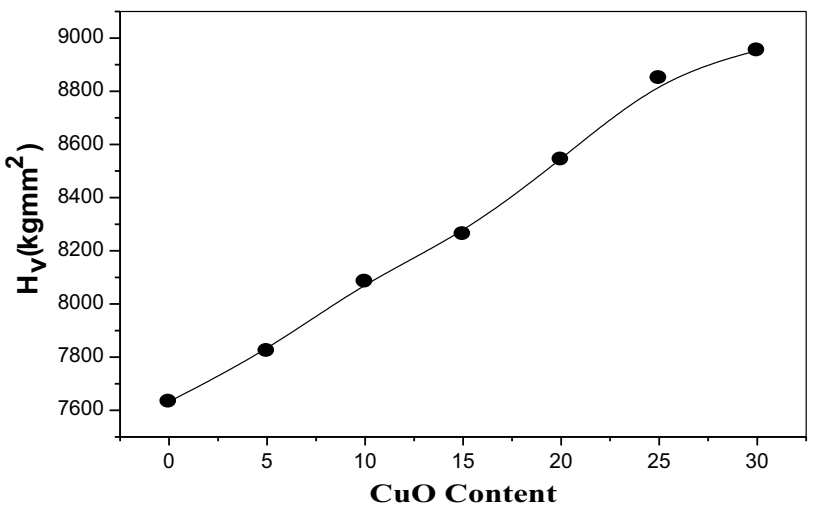

Fig. 8 Vicker hardness $\left(\mathrm{H}_{\mathrm{v}}\right)$ versus $\mathrm{CuO}$ content

1.44 and $1.40 \mathrm{~cm}$ while the MFP of the three commercial radiation shielding glasses produced by SCHOTT (RS 323 G19, RS 360 and RS 520) are 3.57, 3.13 and $2 \mathrm{~cm}$, respectively [37]. It is evident that the MFP values of all the fabricated glasses $\left(\mathrm{CuV}_{1}-\mathrm{CuV}_{7}\right)$ are lower than RS 360, RS $323 \mathrm{G} 19$ and RS 520 glasses. This result suggests that the prepared glasses have higher efficiency in terms of radiation shielding with respect to the selected commercial radiation shielding glass.

\subsection{Hardness}

Microhardness testing is a method of determining a material's hardness or resistance to penetration. Microhardness measurements were performed for the prepared bismuth-silicate glasses within dentation loads at $300 \mathrm{~g}$ to identify the optimal experimental conditions. Figure 8 shows the test results for the present bismuthsilicate glasses. It is clearly seen that the hardness increases gradually with increasing $\mathrm{CuO}$ content. This may indicate that it is behaving like a former and leading to an increase bond rigidity. Consequently, it appears bond rigidity. Also, replacing $\mathrm{CuO}$ by $\mathrm{V}_{2} \mathrm{O}_{5}$ increases the cross-link density as well as the remarkable difference atomic mass of $\mathrm{Cu}$ and $\mathrm{V}$ and consequently the hardness increase. From density results, the increasing in density of glass means that the glass is more cohesive for the raptors forming the network and therefore the hardness makes the glass bear exposure to radiation and the resistance of breakage or scratching. This glass has a more solidity and the strength of its network, so it is a good resistance to radiation.

\section{Conclusions}

The bismuth-silicate glasses with the nominal composition of $x \mathrm{CuO}-(30-x) \mathrm{V}_{2} \mathrm{O}_{5}-50 \mathrm{Bi}_{2} \mathrm{O}_{3}-10 \mathrm{Na}_{2} \mathrm{O}-10 \mathrm{SiO}_{2}$, where $(0 \leq x \leq 30$ wt $\%)$ were prepared successfully using conventional melt quenching method. FTIR spectroscopic analysis showed that the studied glasses contain $\mathrm{BiO}_{3}$ and $\mathrm{BiO}_{6}$ basic structural units. The results of the radiation shielding characteristics of the glasses prepared using the gamma ray spectrometer at different energies show that with the increase of CuO content, a slight increase, whereas HVL and MFP are gradually decreasing, which means that the thickness of the glass used for shielding is low. The effective atomic number value of $\mathrm{CuV}_{7}$ sample is high which contains the higher $\mathrm{CuO}$ concentration. So, the radiation shielding properties for the prepared glasses are being enhanced with increasing $\mathrm{CuO}$ content. Also, the density increases with the $\mathrm{CuO}$ content. Therefore, the glass is more cohesive in the network and there is an increase in the hardness that makes the glass bear exposure to radiation and the resistance of breakage or scratching. All the above results indicate that this glass containing copper oxide can be used as a good resistor of radiation.

\section{Compliance with ethical standards}

Conflict of interest The authors declare that they have no competing interests.

\section{References}

1. Kurudirek M, Chutithanapanon N, Laopaiboon $\mathrm{R}$, Yenchai $\mathrm{C}$, Bootjomchai $\mathrm{C}$ (2018) Effect of $\mathrm{Bi}_{2} \mathrm{O}_{3}$ on gamma ray shielding and structural properties ofborosilicate glasses recycled from high pressure sodium lamp glass. J Alloys Compd 745:355-364

2. Obaid SS, Sayyed MI, Gaikwad DK, Pawar PP (2018) Attenuation coefficients and exposure build up factor of some rocks for gamma ray shielding applications. Radiat Phys Chem 148:86-94

3. Elbashir BO, Dong MG, Sayyed MI, Issa SAM, Matori KA, Zaid MHM (2018) Comparison of Monte Carlo simulation of gamma ray attenuation coefficients of amino acids with XCOM program and experimental data. Results Phys 9:6-11

4. Kurudirek M (2017) Heavy metal borate glasses: potential use for radiation shielding. J Alloys Compd 727:1227-1236

5. Kirdsiri K, Kaewkhao J, Pokaipisit A, Chewpraditkul W, Limsuwan $\mathrm{P}$ (2009) Gamma-rays shielding properties of $x \mathrm{PbO}:(100-x) \mathrm{B}_{2} \mathrm{O}_{3}$ glasses system at662 keV. Ann Nucl Energy 36:1360-1365

6. Hall D, Newhause N, Borelli N, Dumbaugh W, Weidman D (1989) The study of $\mathrm{CuO}-\mathrm{B}_{2} \mathrm{O}_{3}-2 \mathrm{Bi}_{2} \mathrm{O}_{3}$ glasses by spectroscopic techniques. J Appl Phys Lett 54:1293

7. Komatsu T, Matusida K, Termochem S (1991) Thermal decomposition of Mg-Al hydroxides coprecipitated in the presence of oxalate ions. Acta 174:131

8. Mercier C, Palavit G, Montagne L, Follet C (2003) A survey of transition-metal-containing phosphate glasses. Sci Paris 5:693 
9. Tricot G, Montagne L, Delevoye L, Palavit G, Kostoj V (2004) Redox and structure of sodium-vanadophosphate glasses. J Noncryst Solids 345:56-60

10. Vedeanu N, Cozar O, Ardelean I, Lendl B (2006) IR and Raman investigation of $\mathrm{x}(\mathrm{CuO} \cdot \mathrm{V}-2 \mathrm{O})(1-\mathrm{x})\left[\mathrm{P}_{2} \mathrm{O}_{5} \cdot \mathrm{CaF}_{2}\right]$ glass system. J Optoelectron Adv Mater 8(1):78-81

11. Attallah M, Farouk M, El-Korashy A, ElOkr M (2018) Copper doped phosphate glass as an optical band pass filter. Silicon 10(2):547-554

12. Saudi HA, Mostafa AG, Sheta N, El Kameesy SU, Sallam HA (2011) The structural properties of $\mathrm{CdO}-\mathrm{Bi}_{2} \mathrm{O}_{3}$ boro-phosphate glass system containing $\mathrm{Fe}_{2} \mathrm{O}_{3}$ and its role in attenuating neutrons and gamma rays. Phys B Phys Condens Matter 406:4001-4006

13. Saudi HA, El-Kameseey SU (2018) Investigation of modified zinc borate glasses doped with $\mathrm{BaO}$ as a nuclear radiation-shielding material. Radiat Detect Technol Methods 2:44. https://doi. org/10.1007/s41605-018-0075-x

14. Ardelean I (1978) Semiconduction in $x \mathrm{Fe}_{2} \mathrm{O}_{3}(1-\mathrm{x})\left[3 \mathrm{~B}_{2} \mathrm{O}_{3} \cdot \mathrm{PbO}\right]$ glasses. Solid State Common 27:697-703

15. Singh N, Singh KJ, Singh K, Singh H (2006) Gamma-ray attenuation studies of $\mathrm{PbO}-\mathrm{BaO}-\mathrm{B}_{2} \mathrm{O}_{3}$ glass system. Radiat Meas 41:84

16. Singh KJ, Singh N, Kaundal RS, Singh K (2008) Gamma-ray shielding and structural properties of $\mathrm{PbO}-\mathrm{SiO}_{2}$ glasses. Nuclear Instrum Methods Phys Res Sect B Beam Interact Mater Atoms 266:944-948

17. Bagheria R, Moghaddam AK, PezhmanShirmardi S, Azadbakhtd $B$, Salehi $M$ (2018) Determination of gamma-ray shielding properties for silicate glasses containing $\mathrm{Bi}_{2} \mathrm{O}_{3}, \mathrm{PbO}$, and $\mathrm{BaO}$. J Noncryst Solids 479:62-71

18. KulwinderKaur KJ Singh, Anand V (2016) Structural properties of $\mathrm{Bi}_{2} \mathrm{O}_{3}-\mathrm{B}_{2} \mathrm{O}_{3}-\mathrm{SiO}_{2}-\mathrm{Na}_{2} \mathrm{O}$ glasses for gamma ray shielding applications. Radiat Phys Chem 120:63-72

19. Singh VP, Badiger NM, Chanthima N, Kaewkhao J (2014) Evaluation of gamma-ray exposure buildup factors and neutron shielding for bismuth borosilicate glasses. Radiat Phys Chem 98:14-21

20. HuseyinOzanTekin MI Sayyed, Manici T, EbruAltunsoy E (2018) Photon shielding characterizations of bismuth modified borate silicate tellurite glasses using MCNPX Monte Carlo code. Mater Chem Phys 211:9-16

21. Motke SG, Yawale SP, Yawale SS (2002) Infrared spectra of zincdoped leadborate glasses. Bull Mater Sci 25(1):75-78

22. Mostafa AMA, Issa Shams AM, Sayyed MI (2017) Gamma ray shielding properties of $\mathrm{PbO}-\mathrm{B}_{2} \mathrm{O}_{3}-\mathrm{P}_{2} \mathrm{O}_{5}$ doped with $\mathrm{WO}_{3}$. J Alloys Compd 708:294-300

23. RajeshwariMirji BL (2017) Computation of the mass attenuation coefficient of polymeric materials at specific gamma photon energies. Radiat Phys Chem 135:32-44

24. Berger MJ, Coursey JS, Zucker MA, Chang J (1993) ESTAR, PSTAR, and ASTAR: computer programs for calculating stopping-power and range tables for electrons, protons, and helium ions (version 1.2.3). National Institute of Standards and Technology, Gaithersburg, MD, 2005. Originally published as: Berger, M.J., NISTIR
4999, National Institute of Standards and Technology, Gaithersburg, MD. http://physics.nist.gov/Star

25. Hine GJ (1952) The effective atomic numbers of materials for various gamma ray interactions. Phys Rev 85:725

26. Sayyed Ml, Elhouichet $H$ (2017) Variation of energy absorption and exposure buildup factors with incident photon energy and penetrationdepth for boro-tellurite $\left(\mathrm{B}_{2} \mathrm{O}_{3}-\mathrm{TeO}_{2}\right)$ glasses. Radiat Phys Chem 130:335-342

27. Ersundu $A E$, Büyükyıldız $M$, Ersundu $M C ̧$, Şakar $E$, Kurudirek $M$ (2018) The heavy metal oxide glasses within the $\mathrm{WO}_{3}-\mathrm{MoO}_{3}-$ $\mathrm{TeO}_{2}$ system to investigate the shielding properties of radiation applications. Prog Nuclear Energy 104:280-287

28. Sayyed MI, Lakshminarayana G (1018) Structural, thermal, optical features and shielding parameters investigations of optical glasses for gamma radiation shielding and defense applications. J Noncryst Solids 487:53-59

29. Colak SC (2017) Role of titanium ions on the optical and thermal properties of zinc borate glass doped with $\mathrm{TiO}_{2}$. Phys Chem Glass Eur J Glass Sci Technol B 58(1):41-48

30. Ramesh B, Shareefuddina MD, Sayanna R (2016) Synthesis of novel la 0.7 Ce 0.2 Sr 0.1 Fe 0.5 Mn 0.4 Co 0.1 O3 (LCSFMCO). J.Mater Today Proc 3:1914-1922

31. Karthikeyan B, Mohan S (2003) Effect of phosphorus oxide additives on the color and production conditions of $\mathrm{Bi}_{2} \mathrm{O}_{3}-\mathrm{SiO}_{2}-$ $\mathrm{P}_{2} \mathrm{O}_{5}$ glass. Phys B 334:298

32. Davis EA, Mott N (1970) Conduction in non-crystalline systems V. Conductivity, optical absorption and photoconductivity in amorphous semiconductors. Philos Mag 22(179):0903-0922

33. Gomaa HM, Katlawy SM (2017) A new empirical method for estimating the refractive index of oxide glasses using internal structure information. Am J Mater Synth Process 2(6):94-96. https://doi.org/10.11648/j.ajmsp.20170206.14

34. El-Rabaie S, Taha T, Higazy A (2013) Non-linear optical and electrical properties of germanate glasses. J Phys B Condens Matter 429:1-5

35. Yasaka P, Pattanaboonmee N, Kim HJ, Limkitjaroenporn $\mathrm{P}$, Kaewkhao J (2014) Gamma radiation shielding and optical properties measurements of zinc bismuth borate glasses. Ann Nuclear Energy 68:4-9

36. Tijani SA, Kamal SM, Al-Hadeethi Y, Arib M, Hussein MA, Wageh S, Dim LA (2018) Radiation shielding properties of transparent erbium zinc tellurite glass system determined at medical diagnostic energies. J Alloys Compd 741:293-299

37. http://www.schott.com/advanced_optics/english/products/ opticalmaterials/special-materials/radiation-shielding-glass es/index.html

Publisher's Note Springer Nature remains neutral with regard to jurisdictional claims in published maps and institutional affiliations. 